\title{
THE IMPACT OF EMPLOYEES' WORKPLACE INTERACTION ON MARKET-ORIENTED BEHAVIOR
}

Tao Zhu, University of Groningen, the Netherlands

Roger Leenders, University of Groningen, the Netherlands

Wilfred Dolfsma, University of Groningen, the Netherlands

\begin{abstract}
This paper studies individual Market Orientation (MO): still considered inadequately addressed in the literature. Based on earlier arguments in MO theory, we propose that networked interactions are critical drivers of individual MO development. Since currently there is no literature in MO available for this genre of studies, our research contribution can be two fold: First, we provide a new perspective on the still under-studied issue of MO implementation at individual level. Second, this study can also generate direct normative implications for managers. We expected to evaluate a potential driver that is not yet revealed in the MO adapting process as compared with explicit management commitment and financial reward.

We use a data set of 60 firms with 1175 nested individuals of different functions from frontline employees to top managers to test our theoretical proposal. We find that social network effect plays a critical role in the implementation of MO at individual level, more effective than management commitment, financial reward and organizational structure in boosting market information generating and sharing.
\end{abstract}

References available upon request 